\title{
Revealing the nature of black pigments used on ancient Egyptian papyri from Champollion collection
}

\author{
Pierre-Olivier Autran ${ }^{1,2^{*}}$, Catherine Dejoie ${ }^{2}$, Pierre Bordet ${ }^{1}$, Jean-Louis Hodeau ${ }^{1}$, Caroline \\ Dugand $^{3}$, Maëva Gervason ${ }^{3}$, Michel Anne ${ }^{1}$ and Pauline Martinetto ${ }^{1^{*}}$ \\ ${ }^{1}$ Univ. Grenoble Alpes, CNRS, Grenoble, Institut Néel, 38000 Grenoble, France \\ ${ }^{2}$ European Synchrotron Radiation Facility, 71 Avenue des Martyrs, 38000 Grenoble, France \\ ${ }^{3}$ Musée Champollion, Département de l'Isère, 45 Rue Champollion, 38450 Vif, France \\ Keywords: Egyptian papyrus, Champollion, Carbon black, XRD-CT, XRF-CT, SEM, Raman spectroscopy
}

\section{Table of content}

Figure S-1. Papyrus fragments mounted at ID22

Figure S-2. Carbon Raman band fitting and width vs. D band position

Figure S-3. SEM images of peach black and grape black

Figure S-4. Reverse analysis from the ink areas of PAP-8 and PAP-9 (no subtraction)

Table S-1. Elemental composition from XRF

Table S-2. Position and width of the G and D Raman bands

Papyri fragment ownership history, SEM measurements, sample holders for ID22, XRD-CT/XRF-CT data processing. 

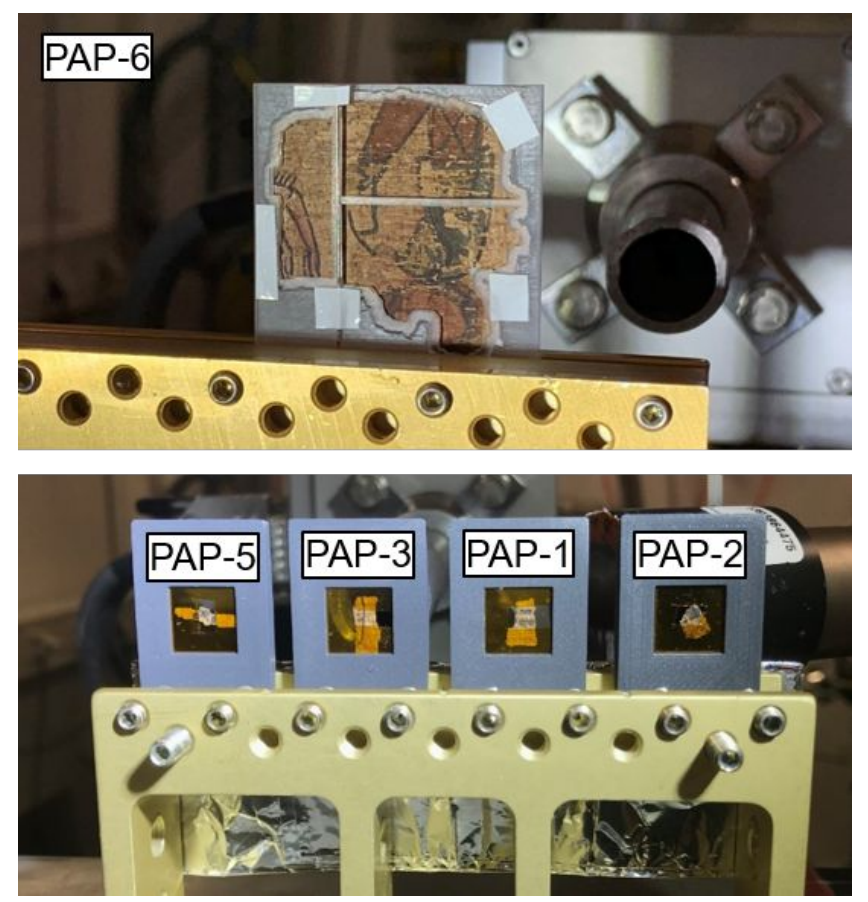

Figure S-1. View of one of the large papyrus fragments (PAP-6) and four of the smaller fragments (PAP-1, PAP-2, PAP-3, and PAP-5) mounted in dedicated 3D-printed sample holders on the experimental stage at the ID22 beamline. 

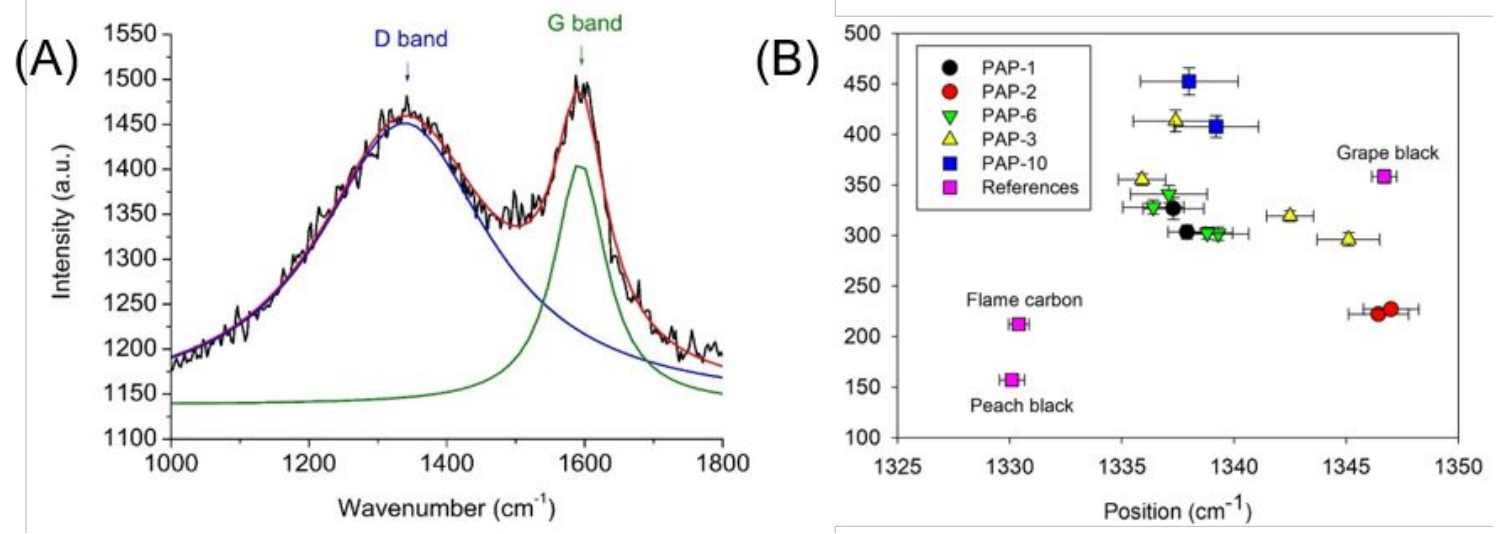

Figure S-2. (A) Fit of the D and G Raman bands of carbon using a 2-band model, (B) Width as a function of position for the D band. 


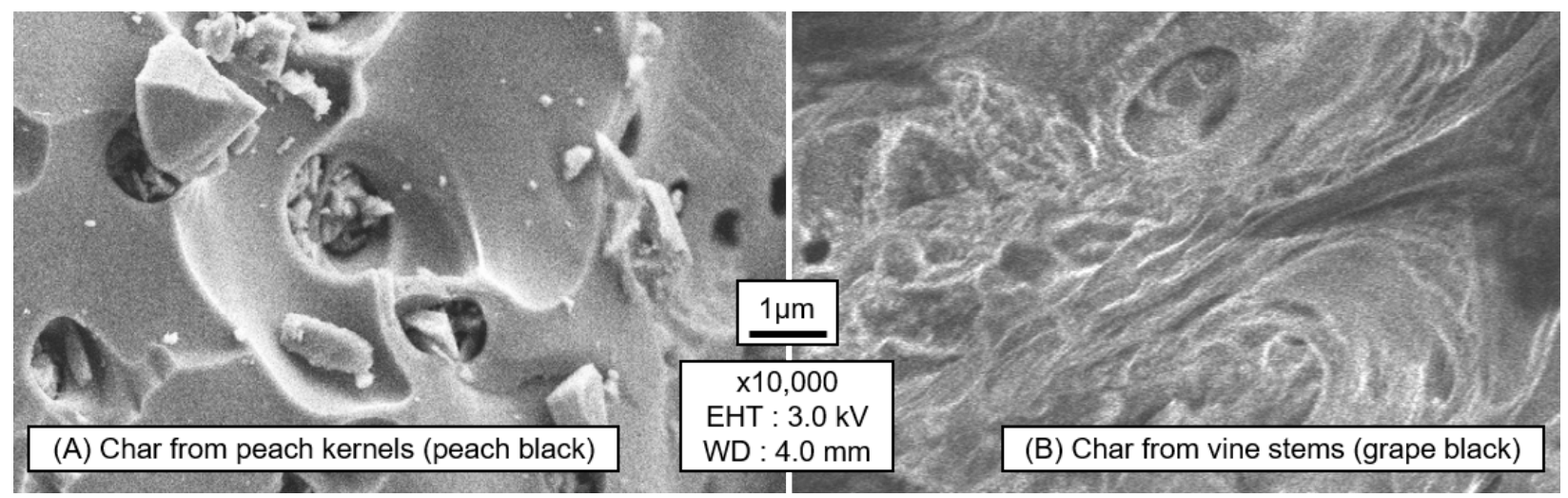

Figure S-3. SEM image of (A) peach black and (B) grape black references. 

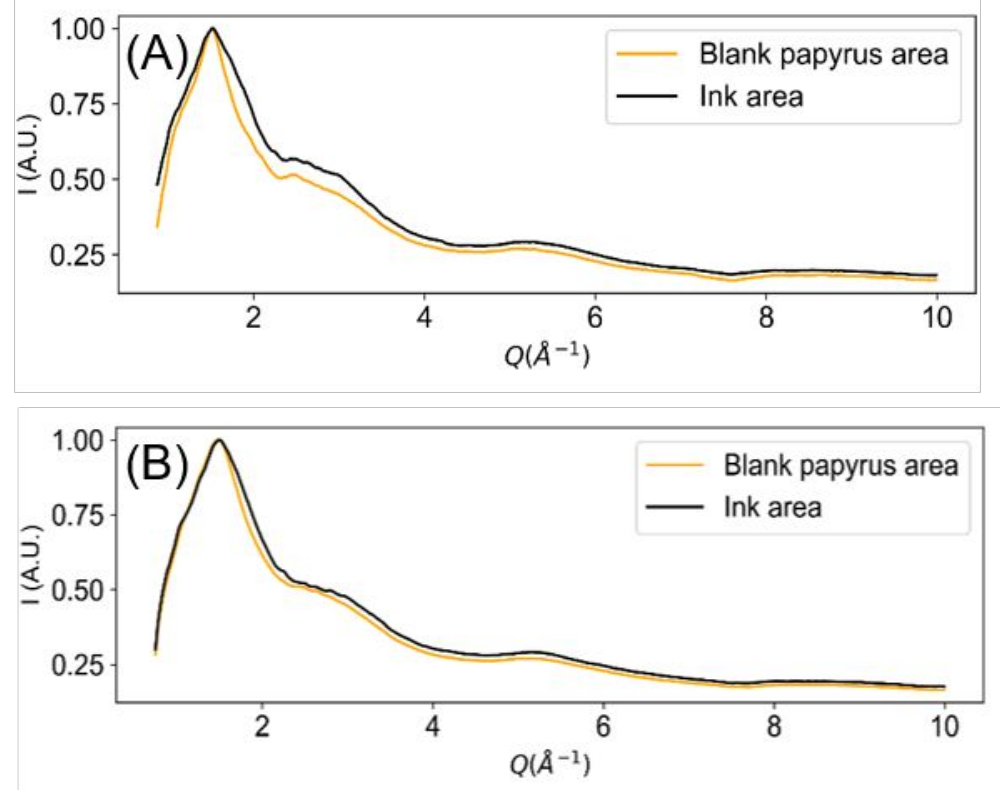

Figure S-4. XRF-CT and XRD-CT reconstructed slices of PAP-8 and PAP-9. (A) and (B) XRD-CT reverse analysis from the ink areas highlighted in orange in Fig. 3B and $\mathrm{E}$ of the main manuscript, respectively. Using the overall diffraction signal of the whole fragment does not lead to any contrast between the ink area and the papyrus support. 
Table S-1. Elemental composition obtained from XRF analyses. For each fragment, several data points (the number of points is indicated in the third column) were collected on both ink and non-ink areas. The resulting values correspond to the average over the number of measured points, with the sum of the eight elements normalized to 100. Because of both detector setup and absorption from the air, only the elements with $Z>18$ were accessible. The energy calibration was achieved by collecting XRF data from iron, copper, silver, molybdenum, and lead foils.

\begin{tabular}{|c|c|c|c|c|c|c|c|c|c|c|}
\hline Sample & Position & No. points & $\mathrm{K}$ & $\mathrm{Ca}$ & $\mathrm{Mn}$ & $\mathrm{Fe}$ & $\mathrm{Cu}$ & $\mathrm{Zn}$ & $\mathrm{Pb}$ & $\mathrm{Sr}$ \\
\hline \multirow[t]{3}{*}{ PAP-1 } & Ink & 4 & $14,7(2,1)$ & $14,6(1,5)$ & $7,6(0,9)$ & $32,1(5,9)$ & $6,1(3,3)$ & $7,1(2,3)$ & $10,5(0,9)$ & $7,4(0,6)$ \\
\hline & No-ink & 4 & $19,2(1,5)$ & $16,7(2,0)$ & $8,2(0,6)$ & $31,7(4,3)$ & $3,6(0,2)$ & $4,8(0,6)$ & $7,9(1,1)$ & $7,7(1,3)$ \\
\hline & \multicolumn{2}{|l|}{ Ratio } & 0.92 & 1.05 & 1.11 & 1.21 & 2.01 & 1.76 & 1.59 & 1.15 \\
\hline \multirow[t]{3}{*}{ PAP-2 } & Ink & 7 & $8,2(0,9)$ & $6,2(1,3)$ & $3,8(0,6)$ & $58,7(5,3)$ & $5,9(1,4)$ & $3,8(0,5)$ & $7,9(1,8)$ & $5,5(1,5)$ \\
\hline & No-ink & 10 & $6,2(0,4)$ & $4,3(0,5)$ & $3,2(0,3)$ & $67,8(21,7)$ & $4,6(1,6)$ & $3,3(0,4)$ & $6,4(0,7)$ & $4,2(0,4)$ \\
\hline & \multicolumn{2}{|l|}{ Ratio } & 1.14 & 1.24 & 1.01 & 0.75 & 1.10 & 0.98 & 1.07 & 1.14 \\
\hline \multirow[t]{3}{*}{ PAP-3 } & Ink & 4 & $12,4(0,9)$ & $17,3(1,6)$ & $6,7(0,2)$ & $31,1(5,0)$ & $4,7(1,4)$ & $3,3(0,6)$ & $11,0(1,7)$ & $13,6(3,8)$ \\
\hline & No-ink & 3 & $9,6(2,9)$ & $9,5(4,1)$ & $4,4(1,6)$ & $47,4(13,8)$ & $4,8(1,8)$ & $2,5(0,5)$ & $14,7(3,0)$ & $7,1(3,3)$ \\
\hline & \multicolumn{2}{|l|}{\begin{tabular}{|l} 
Ratio \\
\end{tabular}} & 1.24 & 1.76 & 1.47 & 0.63 & 0.93 & 1.27 & 0.72 & 1.86 \\
\hline \multirow[t]{3}{*}{ PAP-4 } & Ink & 4 & $13,5(1,1)$ & $12,9(2,2)$ & $12,5(1,2)$ & $38,0(3,7)$ & $3,8(0,3)$ & $3,5(0,6)$ & $7,2(2,9)$ & $8,7(1,1)$ \\
\hline & No-ink & 7 & $13,1(1,0)$ & $13,6(2,1)$ & $13,2(1,6)$ & $35,4(6,4)$ & $4,9(0,6)$ & $3,9(0,7)$ & $7,3(1,0)$ & $8,6(2,0)$ \\
\hline & \multicolumn{2}{|l|}{\begin{tabular}{|l|} 
Ratio \\
\end{tabular}} & 1.12 & 1.03 & 1.02 & 1.15 & 0.82 & 0.96 & 1.06 & 1.08 \\
\hline \multirow[t]{3}{*}{ PAP-5 } & Ink & 5 & $14,6(2,5)$ & $13,0(3,5)$ & $8,0(1,5)$ & $43,9(11,5)$ & $4,8(0,9)$ & $5,0(3,2)$ & $3,0(0,7)$ & $7,7(2,2)$ \\
\hline & No-ink & 7 & $13(2,8)$ & $12,8(3,2)$ & $7,4(0,82)$ & $41,0(7,0)$ & $3,0(0,5)$ & $10,4(7,5)$ & $4,2(1,2)$ & $8,3(3,4)$ \\
\hline & \multicolumn{2}{|l|}{\begin{tabular}{|l} 
Ratio \\
\end{tabular}} & 0.76 & 0.70 & 0.74 & 0.73 & 1.10 & 0.33 & 0.48 & 0.63 \\
\hline \multirow[t]{3}{*}{ PAP-6 } & Ink & 22 & & & $1.0(0,1)$ & $12.0(4.2)$ & $5.2(2.0)$ & $0,5(0,1)$ & $78.8(33,5)$ & $2.5(0,3)$ \\
\hline & No-ink & 55 & & & $1,3(0,2)$ & $16,1(6,3)$ & $5,8(2,4)$ & $0,6(0,1)$ & $72,9(22,5)$ & $3,2(0,5)$ \\
\hline & \multicolumn{2}{|l|}{\begin{tabular}{|l} 
Ratio \\
\end{tabular}} & & & 1.08 & 1.08 & 1.30 & 1.26 & 1.57 & 1.11 \\
\hline \multirow[t]{3}{*}{ PAP-7 } & Ink & 18 & & & $8,1(0,9)$ & $44,8(18,3)$ & $7,6(4,1)$ & $3(0,8)$ & $24,5(7,6)$ & $11,9(3,0)$ \\
\hline & No-ink & 24 & & & $14,5(2,7)$ & $40,9(12,7)$ & $6,0(2,1)$ & $5,0(1,2)$ & $13,1(3,9)$ & $20,4(5,6)$ \\
\hline & \multicolumn{2}{|l|}{ Ratio } & & & 1.14 & 2.25 & 2.59 & 1.25 & 3.84 & 1.20 \\
\hline \multirow[t]{3}{*}{ PAP-8 } & Ink & 439 & $12,5(6,6)$ & $9,8(6,8)$ & $5,1(5,6)$ & $25,3(13,0)$ & $4,2(4,9)$ & $3,2(4,3)$ & $17,3(17,1)$ & $22,5(20,8)$ \\
\hline & No-ink & 787 & $26,1(12,7)$ & $9,5(11,8)$ & $7,4(11,2)$ & $7,0(10,5)$ & $5,9(8,6)$ & $6,5(9,8)$ & $19,9(20,4)$ & $17,8(39,5)$ \\
\hline & \multicolumn{2}{|l|}{ Ratio } & 1.07 & 2.31 & 1.54 & 8.06 & 1.61 & 1.09 & 1.94 & 2.83 \\
\hline \multirow[t]{3}{*}{ PAP-9 } & Ink & 475 & $14,4(12,5)$ & $20,7(23,8)$ & $4,8(6,5)$ & $20,0(24,8)$ & $7,0(12,2)$ & $5,4(10,2)$ & $23,6(18,5)$ & $4,1(6,8)$ \\
\hline & No-ink & 5083 & $19,4(22,0)$ & $15,4(23,2)$ & $6,5(13,2)$ & $28,0(139,4)$ & $7,1(16,5)$ & $9,3(18,3)$ & $10,2(16,4)$ & $4,1(9,8)$ \\
\hline & \multicolumn{2}{|l|}{ Ratio } & 1.20 & 2.18 & 1.19 & 1.16 & 1.60 & 0.94 & 3.76 & 1.61 \\
\hline
\end{tabular}


Table S-2. Position and width of the G and D Raman bands of the carbon-black pigment. One to four spectra were measured on the ink region for each sample, and are reported in the table. A two-peak model with a Lorentzian profile was applied during the fitting process. Results obtained for three reference pigments (flame carbon, peach black, and grape black) are also given.

\begin{tabular}{|l|l|l|l|l|}
\hline Sample & $\begin{array}{l}\text { G band } \\
\text { position } \\
\left(\mathrm{cm}^{-1}\right)\end{array}$ & $\begin{array}{l}\text { G band } \\
\text { width } \\
\left(\mathrm{cm}^{-1}\right)\end{array}$ & $\begin{array}{l}\text { D band } \\
\text { position } \\
\left(\mathrm{cm}^{-1}\right)\end{array}$ & $\begin{array}{l}\text { D band } \\
\text { width } \\
\left(\mathrm{cm}^{-1}\right)\end{array}$ \\
\hline \multirow{2}{*}{ PAP-1 } & $1598.8(9)$ & $72(12)$ & $1337(1)$ & $326(10)$ \\
\cline { 2 - 5 } PAP-2 & $1598.6(6)$ & $71(8)$ & $1338(1)$ & $303(7)$ \\
\cline { 2 - 5 } & $1587.4(8)$ & $88(2)$ & $1346(1)$ & $222(3)$ \\
\hline \multirow{4}{*}{ PAP-3 } & $1587(1)$ & $93(2)$ & $1347(1)$ & $227(3)$ \\
\cline { 2 - 5 } & $1587.0(8)$ & $109(3)$ & $1337(2)$ & $413(10)$ \\
\cline { 2 - 5 } & $1586.9(6)$ & $88(2)$ & $1336(1)$ & $296(6)$ \\
\cline { 2 - 5 } PAP-6 & $1588.2(6)$ & $96(2)$ & $1342(1)$ & $355(6)$ \\
\hline & $1593.1(9)$ & $90(3)$ & $1337(2)$ & $34(5)$ \\
\cline { 2 - 5 } & $1593.4(7)$ & $87(3)$ & $1336(1)$ & $328(7)$ \\
\cline { 2 - 5 } & $1593.5(7)$ & $94(3)$ & $1339(1)$ & $302(7)$ \\
\hline \multirow{2}{*}{ PAP-10 } & $1593(1)$ & $91(2)$ & $1339(1)$ & $302(6)$ \\
\cline { 2 - 5 } & $1594(1)$ & $95(4)$ & $1338(2)$ & $453(13)$ \\
\hline $\begin{array}{l}\text { Flame } \\
\text { carbon }\end{array}$ & $1590.0(7)$ & $81(4)$ & $1330(2)$ & $407(11)$ \\
\hline $\begin{array}{l}\text { Peach } \\
\text { black }\end{array}$ & $1592.4(4)$ & $73(2)$ & $1330.1(6)$ & $212(1)$ \\
\hline $\begin{array}{l}\text { Grape } \\
\text { black }\end{array}$ & $1583.4(6)$ & $154(3)$ & $1346.7(6)$ & $358(7)$ \\
\hline
\end{tabular}




\section{Papyri fragments ownership history}

The papyri fragments were stored in Champollion's family house (Vif, France) for almost two centuries. The house was sold by the descendants of J.-J. Champollion-Figeac (J.-F. Champollion elder brother) to the Département de l'Isère (Auvergne-Rhônes-Alpes region, France) in 2001, including all furniture and a box with the papyri fragments. The papyri fragments now belong to the Champollion museum created by the Département de l'Isère, and located inside the family house. The museum will open to the public in 2021.

\section{SEM measurements}

Papyrus fragments were mounted in a homemade holder to prevent both sample contamination and charging effects. This specific holder is made from two parts, enclosing the papyrus fragment: a bottom part made of aluminum foil, and a top part made from a perforated nickel foil. Nickel was chosen as this element is not expected to be present in the ink or the papyrus support. The holes in the nickel foil were covered by a 200-mesh gold TEM grid welded with silver glue.

An acceleration voltage of $3 \mathrm{kV}$ and a working distance of 4 to $5 \mathrm{~mm}$ were used to record good-quality images of the papyrus surfaces. EDX analyses were performed at an acceleration voltage of $20 \mathrm{kV}$ with an $8 \mathrm{~mm}$ working distance.

\section{Sample holders for synchrotron measurements at the ID22 beamline}

3D-printed frames composed of a container and a cap with a $1 \mathrm{~cm}$-large window were specially designed to hold the fragments PAP-1 to PAP-5 (Fig. S-1). Fragments were clamped in the middle of the frames by folded Kapton foils. The larger fragments (PAP-6 and PAP-7) were held in a customized 3D-printed frame adapted to their shapes, and several silver wires were carefully added to serve both as spatial references and rigidify the supports (Fig. S-1). An Asiga Pico 2 DLP and a Dagoma Neva Magis 3D-printers, both available at the ID22 beamline, were used to 3D-print the holders.

\section{XRD-CT/XRF-CT data processing}

Papyrus fragments PAP-8 and PAP-9 were measured using both the XRD-CT and XRF-CT techniques ${ }^{1,2}$. Data were recorded by scanning the sample keeping fixed rotation angles. 180 rotations were achieved in such a way, collecting both XRD and XRF patterns simultaneously (1s acquisition time per measurement point). Considering the nonuniform shape of the sample (ultra-thin in one direction and large in the other) and to reduce the number of empty images recorded, the number of scanning steps was redefined for each rotation angle, speeding up the acquisition by a factor two. A total of 45000 diffraction images and XRF spectra were collected in approximately $20 \mathrm{~h}$ for each sample (1 slice per sample).

Single-crystal diffraction signals arising from a few micron-size crystals were found on several 2D diffraction images, creating artifacts in the reconstruction of the slices. Their contribution was filtered out using the function 'separate' from the PyFAI library3. The integration of the 2D diffraction images was carried out with PyFAI. All the XRD patterns and XRF spectra were recombined in sinograms according to the scan geometry. A realignment of each line of the sinograms to account for beam drifts during the measurements was implemented using a center of mass correction described by the following formula:

$$
\operatorname{CoM}_{i}=\frac{\sum_{j=1}^{n} x_{j} S_{i, j} B_{i, j}}{\sum_{j=1}^{n} x_{j}}
$$

where $\mathrm{CoM}_{i}$ is the center of mass of line $i$ in the sinogram, $x_{j}$ is the position of $j^{\text {th }}$ pixel in the line, $S_{i, j}$ is the intensity of the $j^{\text {th }}$ pixel in the $i^{\text {th }}$ line of the sinogram, and $B_{i, j}$ the intensity of the $j^{\text {th }}$ pixel in the $i^{\text {th }}$ line of a mask where pixels of air are imposed to 0 and pixels of sample to 1 .

Finally, the FBP algorithm ${ }^{4}$ was run to reconstruct the final image. To extract back the XRD or XRF signal from a specific area of the reconstructed slices, the reverse analysis method ${ }^{1}$ was used (Plot Z-axis Profile tool from Fiji ${ }^{5}$ software). 


\section{References}

(1) Bleuet, P.; Welcomme, E.; Dooryhée, E.; Susini, J.; Hodeau, J.-L.; Walter, P. Probing the Structure of Heterogeneous Diluted Materials by Diffraction Tomography. Nature Mater 2008, 7 (6), 468-472.

(2) Álvarez-Murga, M.; Bleuet, P.; Hodeau, J.-L. Diffraction/Scattering Computed Tomography for ThreeDimensional Characterization of Multi-Phase Crystalline and Amorphous Materials. J Appl Crystallogr 2012, 45 (6), 1109-1124.

(3) Ashiotis, G.; Deschildre, A.; Nawaz, Z.; Wright, J. P.; Karkoulis, D.; Picca, F. E.; Kieffer, J. The Fast Azimuthal Integration Python Library: PyFAI. J Appl Crystallogr 2015, 48 (2), 510-519.

(4) Natterer, F.; Wübbeling, F. Mathematical Methods in Image Reconstruction; Society for Industrial and Applied Mathematics, 2001.

(5) Schindelin, J.; Arganda-Carreras, I.; Frise, E.; Kaynig, V.; Longair, M.; Pietzsch, T.; Preibisch, S.; Rueden, C.; Saalfeld, S.; Schmid, B.; Tinevez, J.-Y.; White, D. J.; Hartenstein, V.; Eliceiri, K.; Tomancak, P.; Cardona, A. Fiji: An Open-Source Platform for Biological-Image Analysis. Nat Methods 2012, 9 (7), 676-682. 